RUDOLFO, Rafael Nunes Pires. Da Common Law ao Ativismo Judicial. Revista Eletrônica Direito e Política, Programa de Pós-Graduação Stricto Sensu em Ciência Jurídica da UNIVALI, Itajaí, v.13, n.2, $2^{\circ}$ quadrimestre de 2018. Disponível em: www.univali.br/direitoepolitica - ISSN 1980-7791

\title{
DA COMMON LAW AO ATIVISMO JUDICIAL
}

\author{
FROM COMMON LAW TO JUDICIAL ACTIVISM
}

\section{Rafael Nunes Pires Rudolfo ${ }^{1}$}

SUMÁRIO: Introdução; 1 Common Law; 2 A origem do termo Ativismo Judicial (Judicial Activism); Considerações finais; Referências da Fontes Citadas.

\section{RESUMO}

O presente artigo visa discutir as origens do fenômeno jurídico conhecido como Ativismo Judicial. Para tanto, foi necessário efetuar uma retrospectiva histórica, para alcançar sua fundamentação: o sistema common law.

Ao final do artigo, pode-se perceber que o sistema common law, que teve suas origens na Inglaterra, se espalhou pelas colônias britânicas. A common law teve grande influência na formação do constitucionalismo norte-americano e do ativismo judicial. Aliás, foi nos Estados Unidos que surgiu o ativismo judicial, após a Suprema Corte demonstrar uma postura considerada ativista em uma série de julgados. A metodologia utilizada foi o método indutivo, com as técnicas do referente, da pesquisa bibliográfica e do fichamento.

PALAVRAS-CHAVE: Common Law; Ativismo Judicial; Constitucionalismo.

\section{ABSTRACT}

The present article aims at discussing the origins of the phenomenon known as Judicial Activism. To do this, was necessary a retrospective, to reach its basis: the common law system.

In the end of this article, it is possible to perceive that the common law system, original from England, had a big influence in the generation of the North American constitutionalism and judicial activism. By the way, the judicial activism was born in the United States of America, after the Supreme Court demonstrate an activist posture in several judicial decisions.

The methodology used was the inductive method, with the referring 's technic, the review literature exploration and categorizing 's technic.

KEYWORDS: Common Law; Judicial Activism; Constitutionalism.

\footnotetext{
1 Mestrando do Programa de Pós-Graduação Stricto Sensu em Ciência Jurídica - PPCJ/UNIVALI ITAJAÍ-SC. Especialista em Direito Processual Civil. Especialista em Direito Penal e Processual Penal. Especialista em Gestão de Negócios Financeiros (MBA). Graduação em Direito. Graduação em Sistemas de Informação. Servidor público estadual (SC). E-mail: rafaelnpr@tjsc.jus.br.
} 
RUDOLFO, Rafael Nunes Pires. Da Common Law ao Ativismo Judicial. Revista Eletrônica Direito e Política, Programa de Pós-Graduação Stricto Sensu em Ciência Jurídica da UNIVALI, Itajaí, v.13, n.2, $2^{\circ}$ quadrimestre de 2018. Disponível em: www.univali.br/direitoepolitica - ISSN 1980-7791

\section{INTRODUÇÃO}

Este artigo tem como objetivo principal, analisar e entender as origens do fenômeno jurídico conhecido como Ativismo Judicial. Para tanto, foi necessário efetuar uma retrospectiva histórica, para alcançar os alicerces de sua fundamentação: o sistema common law. Destarte, no decorrer do artigo, será analisado desde o cenário onde foi concebido o direito inglês ( $e$, consequentemente, a common law), passando pelos principais aspectos históricos primordiais para a consolidação do aludido sistema jurídico. Mister verificar, portanto, desde o contexto da Inglaterra do século XIII. Outrossim, verifica-se que, com grande influência da common law, ocorreu o surgimento e o desenvolvimento do constitucionalismo norte-americano. Aliás, foi com a evolução do constitucionalismo dos Estados Unidos da América que o poder judiciário começa a ganhar evidência, especialmente a Suprema Corte norte-americana. Nesta senda, a referida Corte, a partir do Século XX, começou a exarar algumas decisões importantes, principalmente a favor dos direitos individuais (também em função do advento do judicial review) e foi, gradativamente, alterando sua forma de atuação e crescendo em protagonismo; e começa a exercer influência não só nas instituições, mas também no cenário político; ao passo que, após o término da Segunda Guerra Mundial, o modelo constitucionalista norte-americano e outros fenômenos jurídicos (dentre eles, o ativismo judicial) começam a se propagar pelo restante do mundo, chegando inclusive ao cenário jurídico brasileiro.

O artigo foi organizado em dois capítulos: o primeiro capítulo cuida exclusivamente do sistema common law; ao passo que, o segundo capítulo aborda os aspectos ligados ao ativismo judicial.

A metodologia utilizada foi o método indutivo, com as técnicas do referente, da pesquisa bibliográfica e do fichamento. ${ }^{2}$

2 PASOLD, Cesar Luiz. Metodologia da pesquisa jurídica: teoria e prática. 13. ed. Florianópolis: Conceito Editorial, 2015, p. 56. 
RUDOLFO, Rafael Nunes Pires. Da Common Law ao Ativismo Judicial. Revista Eletrônica Direito e Política, Programa de Pós-Graduação Stricto Sensu em Ciência Jurídica da UNIVALI, Itajaí, v.13, n.2, $2^{\circ}$ quadrimestre de 2018. Disponível em: www.univali.br/direitoepolitica - ISSN 1980-7791

\section{COMMON LAW}

Hodiernamente, há uma classificação do direito em dois diferentes sistemas jurídicos, denominados common law e civil law. Para Giovanni Lobrano, "o direito é caracterizado no mundo contemporâneo por limites lançados por uma exegese meramente interna aos textos codificados, como também a comparação ex post das instituições dos dois grandes sistemas jurídicos". ${ }^{3}$

O sistema de direito conhecido como common law é adotado por mais de 54 países do mundo, sendo os principais: Austrália, Nova Zelândia, Quebec, Índia, Paquistão, Bangladesh, Quênia, Nigéria, Hong Kong, Guiana, Trinidad e Tobago, Barbados e os Estados Unidos da América (em sua maioria, exceto a Louisiana). O sistema do common law é estruturado em torno do precedente judicial, uma vez que é a partir deste que os juízes interpretam a legislação. O Judiciário norteamericano, por exemplo, "possui uma Constituição enxuta, uma carta de princípios, e seu direito baseado em casos, onde cada decisão se torna jurisprudência por ser a expressão da moral da sociedade naquele momento". ${ }^{4}$

$\mathrm{Na}$ tomada de decisões do common law, que de nenhum modo se restringe às instituições jurídicas dos sistemas da common law, como os dos Estados Unidos da América, Inglaterra e Austrália (e que não é necessariamente exaustiva dentre desses sistemas), não se percebe a função judicial como se implicaria primordialmente a aplicação e interpretação de textos canônicos que contém listas de formulações de regras igualmente canônicas. Os juízes do common law tomam decisões aplicando princípios jurídicos contidos em coleções de opiniões judiciais prévias, sendo cada uma dessas opiniões a expressão e justificação escrita da decisão em um caso particular. A medida que aumenta a quantidade destas opiniões, certas justificações se repetem e certos princípios se consolidam. O

3 CAPELLARI, Eduardo. A crise da modernidade e a constituição: elementos para a compreensão do constitucionalismo contemporâneo. Dissertação (Mestrado em Direito) Universidade Federal de Santa Catarina. Florianópolis, 2002, p. 51.

4 SILVA, Andrey Gastaldi; HEIL, Danielle Mariel. Paralelismo da legislação do modelo common law sobre a pena de morte e a redução da maioridade penal no ordenamento jurídico brasileiro. Revista Eletrônica Direito e Política, Programa de Pós-Graduação Stricto Sensu em Ciência Jurídica UNIVALI. Itajaí, v.11, n.3, 30 quadrimestre de 2016, p. 1291. 
RUDOLFO, Rafael Nunes Pires. Da Common Law ao Ativismo Judicial. Revista Eletrônica Direito e Política, Programa de Pós-Graduação Stricto Sensu em Ciência Jurídica da UNIVALI, Itajaí, v.13, n.2, $2^{\circ}$ quadrimestre de 2018. Disponível em: www.univali.br/direitoepolitica - ISSN 1980-7791

resultado disto é o posterior desenvolvimento de uma série de prescrições gerais tais como "os contratos devem basear-se no livre consentimento das partes" e " donos de animais selvagens que machuquem a outros são responsáveis por danos causados, sem importar a culpa". Estas prescrições gerais têm a aparência de regras, e em qualquer sistema de common law bem desenvolvido os advogados possuem a habilidade de referir-se a regras, as opiniões dos juízes citarão regras e os tratados compilarão regras, ao passo que não será possível identificar um conjunto de regras canônicas e dotadas de autoridade referentes aos contratos do modo em que é possível identificar o código impositivo ou as regras do xadrez. Em consequência, com o tempo parecerá que existem "regras" sobre responsabilidade, contratos, propriedades, etc, ainda que o conjunto de tais regras não exista em nenhuma parte de forma canônica e codificada. E mais, essas regras não parecem ser simples descrições de regularidades que têm emergido de decisões particulares anteriores. Consideram-nas prescritivas, e se entende que os juízes da common law estão vinculados a elas. ${ }^{5}$

Nesta mesma esteira é o escólio de Elival da Silva Ramos:

Não obstante, por vezes, nos sistemas de common law as decisões judiciais, para além da concretização do direito em situações fáticas determinadas, assumam a condição de ato veiculador de normas jurídicas (in fieri) balizadoras de conduta e de novos atos de aplicação, não há que se equiparar a função exercida pelos juízes e tribunais com aquela desempenhada pelo legislador, já que o móvel principal da atividade do Poder Judiciário é sempre a solução de um litígio, predominando, pois, a dimensão aplicativa ou executória sobre a criativa ou prescritiva. Tanto é assim que, mesmo nos casos em que há amplo espaço para a movimentação do juiz, por inexistir precedente aplicável ou por existir um texto legislativo vazado em linguagem da qual decorram conceitos amplos e indeterminados, não se comportam os órgãos de jurisdição como um autêntico legislador, tanto mais que estão compelidos, ao contrário deste, a justificar suas decisões, o que fazem lançando mão de argumentação técnico-jurídica

5 SCHAUER, Frederick. Playing by the rules: a philosopical examination of rule-based decisionmaking in law and in life. Oxford University Press, 1991, p. 237-238. Tradução livre. 
RUDOLFO, Rafael Nunes Pires. Da Common Law ao Ativismo Judicial. Revista Eletrônica Direito e Política, Programa de Pós-Graduação Stricto Sensu em Ciência Jurídica da UNIVALI, Itajaí, v.13, n.2, $2^{\circ}$ quadrimestre de 2018. Disponível em: www.univali.br/direitoepolitica - ISSN 1980-7791

(escolha de método de interpretação adequado, integração por meio de princípios gerais de direito ou analogia, etc. ). ${ }^{6}$

Curial enaltecer que no âmago do sistema common law encontra-se o precedente judicial. Aliás, a common law teve origem na Inglaterra, conforme será pontuado mais à frente. No entanto, vale ressaltar que houve diferença na formação do direito inglês e o praticado no restante do continente europeu:

Pode-se dizer que a modernidade chegou um século antes à Inglaterra e que o Direito Inglês (da Inglaterra e do País de Gales) adquiriu sua forma atual por conta desses fatos, com os costumes e os precedentes ocupando lugar de destaque nas fontes primárias do direito daqueles países. É possível dizer que esses traços específicos da formação do ordenamento jurídico e do estado inglês permitiram que o "tempo" do direito consuetudinário (e da produção de teorias políticas que o embasaram) inglês historicamente fosse mais ajustado aos tempos das demais ciências e da sociedade, sem a separação entre direito público e direito privado, tão presente no direito europeu continental moderno, e com um parlamento muito mais voltado para o debate político e para a aprovação de regras gerais, com uma constituição formada por documentos aprovados ao longo da história (é incorreto dizer que a Inglaterra não tem constituição escrita, pois o que não possui é uma constituição organizada em um só documento, mas os documentos que a compõem são escritos, sim!) A maior parte do ordenamento jurídico formado por precedentes jurisprudenciais criados a partir dos costumes, a Inglaterra e o direito inglês podem proporcionar excelentes elementos para reflexão sobre o direito - e o estado - que se tem e o direito - e o estado - que provavelmente se terá. ${ }^{7}$

Vale ressaltar outros períodos históricos que, de certa forma, ajudam a entender porque o direito inglês evoluiu de forma diferente do direito continental europeu: período romano (43 d.C.) à invasão bárbara (407); período bárbaro: da invasão bárbara à reintrodução do cristianismo (597); período anglo-saxão: da reintrodução do cristianismo à conquista normanda (1066); e período normando:

\footnotetext{
${ }^{6}$ RAMOS, Elival da Silva. Ativismo judicial: parâmetros dogmáticos. 2. ed. São Paulo: Saraiva, 2015, p.109.

7 BODNAR, Zenildo; CRUZ, Paulo Márcio. A commolização do direito positivo, o ativismo judicial e a crise do estado. Revista Novos Estudos Jurídicos - Eletrônica. Itajaí, v. 21, n. 3, 2016, p. 1340.
} 
RUDOLFO, Rafael Nunes Pires. Da Common Law ao Ativismo Judicial. Revista Eletrônica Direito e Política, Programa de Pós-Graduação Stricto Sensu em Ciência Jurídica da UNIVALI, Itajaí, v.13, n.2, $2^{\circ}$ quadrimestre de 2018. Disponível em: www.univali.br/direitoepolitica - ISSN 1980-7791

após a conquista normanda. ${ }^{8}$ Neste diapasão, MADRUGA JUNIOR destaca algumas conclusões acerca do ambiente em que se desenvolveu o direito inglês:

O que podemos concluir de todo esse conjunto de elementos que formam o ambiente em que se desenvolverá o sistema jurídico inglês são quatro premissas: 1) a presença romana durante três séculos e meio não gerou uma civilização com características romanas, assim como ocorreu no Continente, especialmente na Itália; 2) o direito romano sobrevivente à queda de Roma, que foi de certa forma recepcionado pelos invasores bárbaros, não deixou de exercer alguma influência nas instituições inglesas a partir da reintrodução do cristianismo entre as tribos anglo-saxônicas e por meio de alguns costumes remanescentes na Normandia e que foram traduzidos pela conquista normanda; 3) a influência do direito canônico na Inglaterra foi menor que no continente, explicando porque o conteúdo moral do direito contratual do civil law, influência do direito canônico, não existe no common law, onde o enforcement das promessas justifica-se mais por razões econômicas; e 4) no sistema feudal inglês, ao contrário do continental, a Coroa manteve certo poder sobre os senhores feudais, o que permitiu, ainda que lentamente, a estruturação de uma common law. ${ }^{9}$

Uma vez entendido o conceito de common law, passa-se agora para uma análise histórica mais detalhada sobre o aludido sistema. Para contextualizar a situação social, não se pode olvidar o cenário:

Na sociedade protomedieval, estática e dominada por um forte naturalismo, o problema da validade do direito não é percebido com força, sendo superado sem dificuldades pela ideia central de fato normativo, e pela concepção de um direito reicêntrico que extrai a sua validade diretamente dos usos e costumes. ${ }^{10}$

\footnotetext{
8 MADRUGA FILHO, Antenor Pereira. A noção de contrato no direito inglês: perspectiva histórica. Revista de Informação Legislativa. Brasília, n. 143, 1999, p. 242. Disponível em: https://www2.senado.leg.br/bdsf/bitstream/handle/id/518/r143-19.PDF?sequence=4. Acesso em 10/07/2017.
}

9 MADRUGA FILHO, Antenor Pereira. A noção de contrato no direito inglês: perspectiva histórica. Revista de Informação Legislativa, p. 246.

10 GUANDALINI JR., Walter. Perspectivas da tradição romanística: passado e futuro do direito romano. Sequência, Florianópolis, n. 70, jun. 2015, p. 171. 
RUDOLFO, Rafael Nunes Pires. Da Common Law ao Ativismo Judicial. Revista Eletrônica Direito e Política, Programa de Pós-Graduação Stricto Sensu em Ciência Jurídica da UNIVALI, Itajaí, v.13, n.2, $2^{\circ}$ quadrimestre de 2018. Disponível em: www.univali.br/direitoepolitica - ISSN 1980-7791

Mister salientar que "o Estado de Direito na common law surge da tradição do direito consuetudinário inglês, que foi selecionada e compilada pelos juízes designados pelo Rei desde o século XIII"11. Destarte, na common law, o direito foi sendo construído a partir das próprias decisões proferidas pelos juízes, ou seja, através da jurisprudência.

Entretanto, ao contrário do modelo que era observado na Idade Média,

"[...] há predeterminação e certa previsibilidade, dada pela organização racional e pela força dos precedentes. Contudo, há superação desses precedentes a novos tempos e circunstâncias". ${ }^{12}$

Como consequência, surge o rule of law, que no escólio de Manoel Gonçalves Ferreira Filho, está fundamentado sobre três pilares:

1) O predomínio absoluto das normas de Direito Comum a todos, o que exclui qualquer poder arbitrário por parte do governo; 2) a igual sujeição a todos (inclusive autoridades) à lei e aos tribunais comuns; 3) a consagração pelo direito comum das liberdades do cidadão, garantidas também pelos tribunais ordinários. ${ }^{13}$

Neste diapasão, sobre uma perspectiva histórica da common law, pode-se dizer, resumidamente, que:

O movimento constitucionalista ganha relevo no início do século XIII, com a assinatura da Magna Carta no reinado de João Sem-Terra (1199-1216), rei da Inglaterra, sendo a luta pela limitação jurídica do poder político e a garantia de liberdades e direitos básicos dos indivíduos as principais contribuições do constitucionalismo. No final do século XVIII, uma profunda alteração na concepção do constitucionalismo alterou a concepção de Constituição, introduzindo um novo

\footnotetext{
11 PINTO, Felipe Chiarello de Souza; DONADELLI, Antonio Paulo de Mattos. O papel do judiciário, o estado de direito e o chamado "ativismo judicial" na doutrina brasileira. Revista Novos Estudos Jurídicos - Eletrônica. Itajaí, v. 19, n. 1, 2014, p. 49.

12 O papel do judiciário, o estado de direito e o chamado "ativismo judicial" na doutrina brasileira. Revista Novos Estudos Jurídicos, p. 49.

13 PINTO, Felipe Chiarello de Souza; DONADELLI, Antonio Paulo de Mattos. O papel do judiciário, o estado de direito e o chamado "ativismo judicial" na doutrina brasileira. Revista Novos Estudos Jurídicos, p. 50.
} 
RUDOLFO, Rafael Nunes Pires. Da Common Law ao Ativismo Judicial. Revista Eletrônica Direito e Política, Programa de Pós-Graduação Stricto Sensu em Ciência Jurídica da UNIVALI, Itajaí, v.13, n.2, $2^{\circ}$ quadrimestre de 2018. Disponível em: www.univali.br/direitoepolitica - ISSN 1980-7791

catálogo de direitos fundamentais, direitos que exigiam prestações positivas por parte do Estado, de modo a compatibilizar os ideais de liberdade, igualdade, solidariedade e fraternidade, na tentativa de fazer com que o mundo se conduza pensando nas futuras gerações. ${ }^{14}$

Sabemos bem o que aconteceu na Inglaterra. O consilium regni, que a princípio só se manifestava na tradicional magna cúria, e só em determinadas situações críticas, em virtude de uma convocação por parte do rei - como no caso do parlamento de Westminster de 1254 ou do parlamento de Oxford de 1258 -, transforma-se gradualmente, de maneira estável e institucionalizada, no parlamento da Inglaterra, que assim é chamado de maneira cada vez mais frequente no curso do século XIII. Um parlamento no qual, junto ao rei, tenderam estar representadas todas as mais significativas instituições políticas e realidades territoriais do reino, qualificadas de aristocracia, mas também expressão das comunidades rurais e urbanas, na linha que progressivamente conduzirá à estruturação do parlamento através das conhecidíssimas assembleias dos Lords e dos Commons. No ano de 1322 podia ler-se a seguinte declaração do parlamento inglês: Tudo o que deve se decidir pelo reino e pela totalidade da comunidade política, deve ser discutido e determinado no parlamento, pelo rei nosso senhor, com o consenso dos prelados, dos condes, dos barões e dos commoners do reino, segundo o antigo costume. ${ }^{15}$

Em 1607, o juiz Sir Edward Coke, um dos ícones da tradição do common law, escreveu sustentando que nem sequer ao Rei se permitiria ser o juiz de um caso jurídico, ao dizer que ainda que Deus tenha dotado Sua Majestade com excelente ciência e grandes dons de natureza, era certo que Sua Majestade não estava instruída nas leis de seu reino da Inglaterra, e às causas que concernem à vida, herança, bens ou fortuna de seus súditos, não tem de ser decididas segundo a razão natural, mas pela razão artificial e o juízo do direito, o qual é uma arte que

\footnotetext{
14 MENEZES, Flavia Ferreira Jocó de; SILVA, Alexandre Garrido da. Poder judiciário e diálogos institucionais: uma perspectiva frente à flexibilização das decisões. Horizonte Científico, vol. 8, n. 1 , julho de 2014 , p. 3.

15 FIORAVANTI, Maurizio. Constitución: De la Antiguidad a nuestros días. Tradução de Manuel Martínez Neira. Madrid: Trotta, 2001, p. 51. Tradução livre.
} 
RUDOLFO, Rafael Nunes Pires. Da Common Law ao Ativismo Judicial. Revista Eletrônica Direito e Política, Programa de Pós-Graduação Stricto Sensu em Ciência Jurídica da UNIVALI, Itajaí, v.13, n.2, $2^{\circ}$ quadrimestre de 2018. Disponível em: www.univali.br/direitoepolitica - ISSN 1980-7791

requer prolongados estudos e experiência antes de que um homem possa lograr conhece-lo. ${ }^{16}$

Graças sobretudo à figura de Edward Coke (1552-1634), essa mesma lei fundamental, essa mesma constituição antiga emerge em um plano mais diretamente jurídico-normativo, na qualidade de common law, capaz de circunscrever, através da obra dos juízes, a força da mesma lei do parlamento. Segundo Coke, se este parlamento tivesse traindo sua natureza - profundamente medieval - de alta corte de justiça, os juízes não teriam que duvidar em aplicar sua lei; e dessa maneira teriam que trabalhar, com o instrumento da interpretação, para reconduzir esta lei, segundo a expressão mais recorrente da obra de Coke, a uma dimensão e a um significado conforme as ancient common laws and customs of the realm, às antigas leis comuns e costumes do reino. Na realidade, o que se defende é esse conjunto de leis profundamente radicadas na história da comunidade política, de costumes, de pactos e de acordos entre os distintos componentes do reino, que em seu conjunto dão como resultante a lei fundamental, a common law, a mesma constituição, em uma palavra. Não uma norma abstrata, por algum misterioso motivo superior à lei do parlamento, como se estivesse aqui antecipando a moderna hierarquia das fontes do direito e o moderno controle de constitucionalidade, mas uma norma que corresponde à história do reino e de suas múltiplas articulações sociais e institucionais, que o parlamento, em sua função tradicional de alta corte de justiça, deve manter em equilíbrio emanando leis justas que reconheçam o direito de cada um, que não privilegia ou penalize de maneira arbitrária. Esta é a função dos juízes de Coke, colocados como sentinelas no coração do sistema constitucional, com a finalidade de garantir que a mais alta expressão desse sistema, o mesmo parlamento, não troque sua natureza, não traia sua missão. ${ }^{17}$

\footnotetext{
${ }^{16}$ SCHAUER, Frederick. The force of law. Harvard University Press, 2015, p. 358. Tradução livre.

${ }^{17}$ FIORAVANTI, Maurizio. Constitución: De la Antiguidad a nuestros días, p. 66 a 68 . Tradução livre.
} 
RUDOLFO, Rafael Nunes Pires. Da Common Law ao Ativismo Judicial. Revista Eletrônica Direito e Política, Programa de Pós-Graduação Stricto Sensu em Ciência Jurídica da UNIVALI, Itajaí, v.13, n.2, $2^{\circ}$ quadrimestre de 2018. Disponível em: www.univali.br/direitoepolitica - ISSN 1980-7791

Concluída a análise do surgimento da common law, insta frisar como o aludido sistema jurídico se propagou para além dos limites de seu berço, atravessando o Oceano Atlântico, até os Estados Unidos da América. Sir Edward Coke figura como um dos personagens principais nesta história.

É praticamente certo que a extensão do common law inglês às costas norteamericanas se deve a Sir Edward Coke, o animoso jurista que, viu na common law, mais que no Parlamento, a garantia mais eficaz contra o absolutismo. Os colonos, desta maneira, herdaram um direito que, no clima cultural da época, era sinônimo de liberdade, de uma liberdade que começaram rapidamente a defender. ${ }^{18}$

A Revolução americana, no plano constitucional, representou na realidade o conflito entre duas concepções distintas do poder legislativo: a propagada por Coke e Locke, do legislativo limitado, e a teorizada por Hobbes e Blackstone, do legislativo legibus solutus; ou, entre a teoria medieval da supremacia da lei e a moderna teoria da soberania. Por um lado, as constituições americanas previam toda uma série de direitos dos cidadãos, mas não previam remédio legal algum se caso as assembleias os violassem; por outro lado, a Constituição federal não previa procedimentos que permitissem dirimir o sempre possível conflito entre estados e Estado federal, dado que haviam repartido a soberania sobre o mesmo povo. Era necessário, desta forma, encontrar um árbitro, tanto para limitar o legislativo, como por esta nova força de divisão de poderes entre as assembleias estatais e as assembleias federais, capaz de garantir plena eficácia às normas da constituição, que atribuíam direitos e deveres tanto aos estados como ao Estado federal. E é precisamente na busca desse árbitro donde se encontram as linhas do constitucionalismo americano: assim como, contra a omnipotência do Parlamento, se exaltou a função dos tribunais judiciais de não aplicar as leis anticonstitucionais, da mesma maneira, contra o perigo de um abuso de poder por parte das diversas assembleias coexistentes sobre um mesmo território, se atribuía ao poder judicial

18 MATTEUCCI, Nicola. Organización del poder y libertad: Historia del constitucionalismo moderno. Tradução de F. J. Ansuatpegui Roig e M. Martínez Neira. Madrid: Trotta, 1998, p. 182. Tradução livre. 
RUDOLFO, Rafael Nunes Pires. Da Common Law ao Ativismo Judicial. Revista Eletrônica Direito e Política, Programa de Pós-Graduação Stricto Sensu em Ciência Jurídica da UNIVALI, Itajaí, v.13, n.2, $2^{\circ}$ quadrimestre de 2018. Disponível em: www.univali.br/direitoepolitica - ISSN 1980-7791

a tarefa de garantir tanto aos estados como ao Estado federal o exercício dos direitos que Ihes atribuía a constituição. As duas linhas se encontram e confluem no mesmo resultado: o fortalecimento do poder judicial, como guardião e intérprete da constituição. O absolutismo europeu, que havia visto o soberano desvinculado das leis, resta derrotado. ${ }^{19}$

Até 1776, o common law inglês, modificado por alguns ajustes locais, tinha regido casos legais nos Estados Unidos. Pessoas ainda processavam umas às outras, faziam contratos e escreviam testamentos. Então surge uma nova questão: que lei aplicar? Com fidelidade à coroa terminada, a lei inglesa ainda continuaria no controle das cortes americanas e como poderia esta determinação ser feita? Embora alguns patriotas quisessem estabelecer uma nova base para a lei americana, a common law inglesa compreendia a única lei que a maioria dos advogados e juízes americanos conheciam. Enquanto denunciavam a política legislativa britânica, americanos da maioria das partes defendia a common law, aguardando somente purificá-la da "corrupção" de George III. Eles reverenciavam a common law como exposto no constitucionalismo de Sir Edward Coke. Quando o Primeiro Congresso Continental adotou a Declaração de Direitos, em 1776, foi declarado que as colônias designaram a common law da Inglaterra, para o benefício daqueles estatutos ingleses que já existiam ao tempo de colonização; e a qual eles tinham, por experiência, respectivamente encontrado ser aplicável à diversas circunstâncias locais. Um estado após o outro adotou esta visão. Por vários estatutos "recepcionados", a lei americana recebeu e incorporou a commom law inglesa, o que providenciou uma ligação de continuidade entre a lei colonial e o desenvolvimento pós-revolucionário. Muitos destes estatutos ainda são encontrados em códigos estaduais americanos. Os estados não só aderiram à common law, mas nas cidades advogados e juízes começaram a utilizar cada vez mais como guia legal o quarto volume de Commentaries on the Laws of England (1765-1769) de Sir William Blackstone. As interpretações de Blackstone influenciaram profundamente a lei americana por gerações, e enquanto uma

19 MATTEUCCI, Nicola. Organización del poder y libertad: Historia del constitucionalismo moderno, p. 168. Tradução livre. 
RUDOLFO, Rafael Nunes Pires. Da Common Law ao Ativismo Judicial. Revista Eletrônica Direito e Política, Programa de Pós-Graduação Stricto Sensu em Ciência Jurídica da UNIVALI, Itajaí, v.13, n.2, $2^{\circ}$ quadrimestre de 2018. Disponível em: www.univali.br/direitoepolitica - ISSN 1980-7791

adesão servil a alguns de seus enunciados produziu curiosas anomalias de lei na fronteira, sua filosofia básica se adequava perfeitamente com as necessidades americanas. $^{20}$

A common law é sempre o ponto comum de partida dos colonos americanos: uma herança que certamente será modificada, mas não posta em crise pela experiência da fronteira e de uma sociedade aberta. Se levar-se a cabo uma racionalização e uma codificação, está é uma racionalização e uma codificação da common law que, justamente por isto, consegue conservar algumas características e algumas instituições do direito inglês dos anos 1600. Existe um ponto em que se procede uma ruptura entre as colônias e a pátria-mãe: a necessidade de consenso do rei para a validade de novos documentos jurídicos. Mas estas tensões pertencem a outra parte da história: a história da independência, certamente; mas também as origens do judicial review. ${ }^{21}$

Abominando a veneração que William Blackstone professava sobre a common law ${ }^{22}$ e a celebração que Edward Coke tinha de sua "razão artificial", Bentham considerou a common law como um pouco mais que uma conspiração entre advogados e juízes para fazer do direito algo desnecessariamente complexo e obscuro. $^{23}$

Devemos ter em mente que Blackstone era um juiz, e um juiz em um sistema de common law, no qual os juízes retinham o poder de criar e modificar o direito. $\mathrm{E}$ para um juiz - Blackstone, por exemplo - fazer colapsar o direito que é, com o que deve ser, pode não resultar tão surpreendente. Depois de tudo, se tens o poder de fazer e refazer o direito, então tua opinião sobre o que o direito deve ser,

20 UROFSKY, Melvin I.; FINKELMAN, Paul. A march of liberty: a constitutional history of the United States. 2. ed., 2002, p. 74 a 76. Tradução livre.

21 MATTEUCCI, Nicola. Organización del poder y libertad: Historia del constitucionalismo moderno, p. 204. Tradução livre.

22 Blackstone descreveu o common law como "o melhor direito de nascimento e a mais nobre herança da humanidade". Conforme SCHAUER, Frederick. The force of law, p. 77. Tradução livre.

${ }^{23}$ SCHAUER, Frederick. The force of law, p. 77. Tradução livre. 
RUDOLFO, Rafael Nunes Pires. Da Common Law ao Ativismo Judicial. Revista Eletrônica Direito e Política, Programa de Pós-Graduação Stricto Sensu em Ciência Jurídica da UNIVALI, Itajaí, v.13, n.2, $2^{\circ}$ quadrimestre de 2018. Disponível em: www.univali.br/direitoepolitica - ISSN 1980-7791

pode e deveria, dissolver-se no que o direito é. No sistema de common law não há nenhuma distinção muito clara entre dizer que uma solução particular para um problema é conforme um direito e dizer que é uma solução racional, equitativa ou justa. Mas se tens tua própria valoração sobre o que é racional, equitativo e justo, e se crês que os juízes, ao buscar o racional, equitativo e justo, provavelmente se equivocaram, então certamente não quererás ver o direito através dos olhos dos juízes. ${ }^{24}$

A common law, entretanto, teve que ser americanizada, um processo que por sua natureza seria evolucionária e levaria várias décadas. Poucas mudanças seriam vistas imediatamente; fechar as cortes reais e sua substituição, dentro de poucos anos, por cortes estatais, constituiu a mais visível diferença entre a lei prérevolucionária e pós-revolucionária. ${ }^{25}$

\section{A ORIGEM DO TERMO ATIVISMO JUDICIAL (JUDICIAL ACTIVISM)}

Mister enaltecer, inicialmente, a definição do termo ativismo judicial. No escólio de Luís Roberto Barroso, ativismo judicial se consubstancia em uma "participação mais ampla e intensa do Judiciário na concretização dos valores e fins constitucionais, com maior interferência no espaço de atuação dos outros dois Poderes". ${ }^{26}$

Por seu turno, Elival da Silva Ramos magistralmente conceitua o termo como "o exercício da função jurisdicional para além dos limites impostos pelo próprio ordenamento" ou a "ultrapassagem das linhas demarcatórias da função jurisdicional". 27

\footnotetext{
${ }^{24}$ SCHAUER, Frederick. The force of law, p. 94. Tradução livre.

25 UROFSKY, Melvin I.; FINKELMAN, Paul. A march of liberty: a constitutional history of the United States, p. 77. Tradução livre.
}

26 BARROSO, Luís Roberto. Curso de direito constitucional contemporâneo: os conceitos fundamentais e a construção do novo modelo. São Paulo: Savaiva, 2009, p. 283.

27 RAMOS, Elival da Silva. Ativismo judicial: parâmetros dogmáticos, p. 308 
RUDOLFO, Rafael Nunes Pires. Da Common Law ao Ativismo Judicial. Revista Eletrônica Direito e Política, Programa de Pós-Graduação Stricto Sensu em Ciência Jurídica da UNIVALI, Itajaí, v.13, n.2, $2^{\circ}$ quadrimestre de 2018. Disponível em: www.univali.br/direitoepolitica - ISSN 1980-7791

O termo Ativismo Judicial (Judicial Activism), no escólio de Saul Tourinho Leal, foi utilizado pela primeira vez pelo jornalista norte-americano Arthur Schlesinger Jr, em 1947, numa publicação na revista Fortune. Na aludida publicação, o jornalista classificou os juízes da Suprema Corte dos Estados Unidos - no tocante à atuação destes no controle de constitucionalidade das leis do "New Deal"28 do Presidente Franklin Delano Roosevelt - como ativistas judiciais. A partir de então, a expressão cunhada por Schlesinger Jr. tornou-se conhecida como determinada forma de atuação judicial. $^{29}$

Urge frisar que há divergência quanto à primeira utilização do termo "ativismo judicial". Nesta senda, o termo já teria sido utilizado pela imprensa belga em 1916. De qualquer forma, o termo se consagrou realmente após algumas decisões de grande destaque da Suprema Corte norte-americana. Destarte, conforme magistralmente assevera Dierle José Coelho Nunes, uma "percepção sociológicaeconômica e protagonista do Juiz já era defendida por vários estruturadores da socialização processual, desde o final do século XIX, com destaque para Franz Klein em palestra em 1901".30

Conquanto a publicação do jornalista Arthur Schlesinger Jr. seja considerada como "marco inicial" do ativismo judicial, principalmente em função da aparição da nomenclatura em testilha, não se pode olvidar que tal publicação não se confunde com a primeira manifestação do mencionado fenômeno jurídico. Aliás, suas raízes estão vinculadas ao common law.

Vale ressaltar que enquanto fenômeno é verificado desde o paradigmático caso Marbury vs. Madison, de 1803, quando decisão do Chief Justice John Marshall,

\footnotetext{
28 O New Deal foi um conjunto de medidas baseadas no Estado do bem-estar Social (Welfare State), com o objetivo de incrementar a intervenção econômica do Estado, bem como investir na saúde pública, assistência social e previdência social. Conforme KERTZMAN, Ivan. Curso prático de direito previdenciário. 11. ed. Salvador: Juspodivm, 2014, p.43.
}

29 SOLIANO, Vitor. Ativismo judicial no Brasil: uma definição. Revista Eletrônica Direito e Política, Programa de Pós-Graduação Stricto Sensu em Ciência Jurídica da UNIVALI. Itajaí, v.8, n.1, 10 quadrimestre de 2013, p.591.

30 NASCIMENTO, Aline Trindade do; WEIERS, Karine Schultz. Considerações sobre o ativismo judicial no Brasil. Revista Eletrônica Direito e Política, Programa de Pós-Graduação Stricto Sensu em Ciência Jurídica da UNIVALI. Itajaí, v.12, n. 1, 10 quadrimestre de 2017, p. 295. 
RUDOLFO, Rafael Nunes Pires. Da Common Law ao Ativismo Judicial. Revista Eletrônica Direito e Política, Programa de Pós-Graduação Stricto Sensu em Ciência Jurídica da UNIVALI, Itajaí, v.13, n.2, $2^{\circ}$ quadrimestre de 2018. Disponível em: www.univali.br/direitoepolitica - ISSN 1980-7791

através do "Judicial Review"31 e, mediante a instituição do celebre conceito de que "o governo dos Estados Unidos é um governo de leis e não um governo de homens". ${ }^{32}$ O então presidente norte-americano, Thomas Jefferson, teve uma série de conflitos contra o judiciário federal americano, sendo o mais emblemático o que deu causa a Marbury vs. Madison, conhecido como "Judiciary Act"33 de $1801 .{ }^{34}$

Aliás, "muito antes de Marbury X Madison, houve exemplos de juízes de cortes estaduais anunciando $o$ poder das cortes de anular legislação infraconstitucional". 35

Urge frisar que tais decisões, muitas vezes, adotaram o judicial review sem "nenhum parâmetro legal escrito; ao invés disso, eles baseiam a autoridade dos juízes para controlar a legislação nos princípios do Common Law". ${ }^{36}$

31 "Nos Estados Unidos, o "judicial review" é entendido, desde Marbury v. Madison (1803), como a avaliação judicial de atos governamentais para assegurar a compatibilidade com a Constituição. Mas antes e depois do caso Marbury, cortes estaduais e federais desenvolveram e praticaram uma espécie de "judicial review" no qual os princípios da Common Law, conjuntamente ou ao invés de um cânon documental, onde se utiliza o corpo fundamental da doutrina jurídica para avaliar as ações públicas. " Conforme EDLIN, Douglas E. "Judicial Review" sem uma constituição escrita. Cadernos do Programa de Pós-Graduação Direito/UFRGS, volume 10, n. 1, 2015, p. 1.

32 GONDIM, Yuri. O caso Marbury vs. Madison e a contribuição de John Marshall. Jusbrasil, 2014. Disponível em:< https://yurigondim.jusbrasil.com.br/artigos/118688828/o-caso-marbury-vsmadison-e-a-contribuicao-de-john-marshall. >. Acessado em 10 de março de 2017.

33 "O Judiciary Act alterou o antigo sistema da Suprema Corte e aumentou o número de juízes em outras jurisdições. Jefferson considerou que este ato aumentaria a jurisdição das cortes federais e isso também criaria novos cargos que seriam preenchidos por juízes federalistas, haja vista que já haviam sido nomeados pelo Presidente John Adams às vésperas do final de seu mandato. Jefferson compreendeu o Judiciary Act como um "uso fraudulento da Constituição, que tornou juízes irremovíveis multiplicando cargos inutilmente meramente para aumentar sua legião". William Marbury e outros três juízes do Distrito de Columbia, aos quais Jefferson recusou-se a dar posse, decidiram testar a legalidade da decisão da administração, ajuizando uma ação na Suprema Corte e pedindo que Madison, secretário de Estado de Jefferson, desse-lhes posse de suas funções". Conforme CONSANI, Cristina Foroni. O constitucionalismo republicano de Thomas Jefferson. Revista Novos Estudos Jurídicos - Eletrônica. Itajaí, v. 19, n. 3, 2014, p. 1085.

34 CONSANI, Cristina Foroni. O constitucionalismo republicano de Thomas Jefferson. Revista Novos Estudos Jurídicos, p. 1084.

35 EDLIN, Douglas E. "Judicial Review" sem uma constituição escrita. Cadernos do Programa de Pós-Graduação Direito/UFRGS, p. 10.

${ }^{36}$ EDLIN, Douglas E. "Judicial Review" sem uma constituição escrita. Cadernos do Programa de Pós-Graduação Direito/UFRGS, p. 10. 
RUDOLFO, Rafael Nunes Pires. Da Common Law ao Ativismo Judicial. Revista Eletrônica Direito e Política, Programa de Pós-Graduação Stricto Sensu em Ciência Jurídica da UNIVALI, Itajaí, v.13, n.2, $2^{\circ}$ quadrimestre de 2018. Disponível em: www.univali.br/direitoepolitica - ISSN 1980-7791

Mister salientar que com o advento da "modern era"37 (era moderna) do judicial review - que aliás teve como destaque, na lição de Christopher Wolfe, um "protagonismo judicial, no qual é reforçada a característica destacadamente legislativa das Cortes" - houve uma mudança de postura dos juízes. Nesta senda, "inseridos na common law, os juízes" começaram a reescrever as leis. ${ }^{38}$

Aliás, imperioso salientar que, no entendimento de Gerald Guinther, pode-se inferir que há grande desvirtuamento do que hoje se entende por judicial review, quando se faz uma analogia com o que naquela época pretendia "Marshall quando introduziu o controle de constitucionalidade, pois sua ideia nasce não de uma noção de sobreposição do Judiciário, mas de um agir enquanto pertencente a determinado sistema jurídico". ${ }^{39}$

Vale ressaltar que, após a Segunda Guerra Mundial, constatou-se um crescimento da justiça constitucional, baseada no judicial review ou no constitutional review (este europeu e aquele americano). Como consequência, houve uma "proliferação de modelos e recíproca hibridização" e "uma infinidade de novos esquemas e novas categorias" doutrinários na tentativa de contemplar a jurisdição constitucional. ${ }^{40}$

Ronald Dworkin, ao examinar o fenômeno do ativismo judicial na sociedade norteamericana, destaca que, "em décadas recentes, as principais batalhas" relacionadas à democracia "têm sido contra a autoridade dos juízes e da Suprema

37 "Acreditava-se que se iniciaria uma nova fase na história do exercício da jurisdição nos Estados Unidos, contudo, significou apenas uma mudança de foco: o ativismo judicial direciona-se, da defesa do direito à propriedade, para a das liberdades civis. Portanto, apenas no pós-1937 é que, efetivamente, será possível visualizar o início da "modern era" do judicial review". Conforme TASSINARI, Clarissa. Ativismo judicial: uma análise da atuação do Judiciário nas experiências brasileira e norte-americana. Dissertação (Mestrado em Direito). Universidade do Vale do Rio dos Sinos. São Leopoldo, 2012, p. 75.

38 TASSINARI, Clarissa. Ativismo judicial: uma análise da atuação do Judiciário nas experiências brasileira e norte-americana, p. 75.

39 TASSINARI, Clarissa. Ativismo judicial: uma análise da atuação do Judiciário nas experiências brasileira e norte-americana, p. 75-76.

40 ALVES, Fernando de Brito. Jurisdição constitucional e participação popular: sobre a possibilidade de novas relações entre o judiciário e o legislativo. Revista Novos Estudos Jurídicos - Eletrônica. Itajaí, v. 19, n. 2, 2014, p. 499. 
RUDOLFO, Rafael Nunes Pires. Da Common Law ao Ativismo Judicial. Revista Eletrônica Direito e Política, Programa de Pós-Graduação Stricto Sensu em Ciência Jurídica da UNIVALI, Itajaí, v.13, n.2, $2^{\circ}$ quadrimestre de 2018. Disponível em: www.univali.br/direitoepolitica - ISSN 1980-7791

Corte para declarar a inconstitucionalidade dos atos" de diversos órgãos governamentais. ${ }^{41}$

Neste sentido, mister enaltecer que:

Foi a partir do século XX que a Suprema Corte norteamericana revelou uma atuação mais explicita em favor da efetivação dos direitos individuais, por meio do acolhimento de teses nesse sentido, notadamente em sede de revisão judicial (o século XX, na história da Suprema Corte, apenas para citar - e antecipar - alguns exemplos, foi marcado pela Era Lochner e pela lendária Corte Warren). Na verdade, a capacidade de os juízes e de os tribunais estadunidenses influírem no funcionamento das suas instituições é enorme e parece aumentar com o passar do tempo. Todavia, este não é um fenômeno exclusivo ou particular do modelo norteamericano; pelo contrário, o constitucionalismo europeu, notadamente no segundo pós-guerra, também passou a apresentar característica bastante ampliativa da atuação dos Tribunais Constitucionais $[\ldots] .^{42}$

Percebeu-se um incremento significativo do Poder Judiciário e da jurisdição constitucional, após o término da Segunda Guerra Mundial. Aliás, durante décadas, o paradigma americano de constitucionalismo se espalhou, ao passo que "suas características de centralidade da Constituição, controle judicial de constitucionalidade e judicialização das controvérsias envolvendo direitos fundamentais" podem ser observadas nas mais diversas cortes e constituições do mundo. ${ }^{43}$

A tendência atual é de aproximação entre os dois grandes sistemas jurídicos, conforme o escólio de LOSANO:

${ }^{41}$ RUDOLFO, Rafael Nunes Pires; PAVANELLO, Eliane. Ativismo judicial e o transporte público individual. Disponível em <https://jus.com.br/artigos/57229/ativismo-judicial-e-o-transportepublico-individual/1>. Acesso em: 17/07/2017.

42 NISTLER, Regiane. A judicialização da política e a efetividade dos direitos sociais. Revista Eletrônica Direito e Política, Programa de Pós-Graduação Stricto Sensu em Ciência Jurídica da UNIVALI. Itajaí, v.11, n.1, 10 quadrimestre de 2016, p. 202-203.

43 BARROSO, Luis Roberto. A razão sem voto: a função representativa e majoritária das cortes constitucionais. Revista Estudos Institucionais. Itajaí, vol. 2, n. 2, 2016, p. 541. 
RUDOLFO, Rafael Nunes Pires. Da Common Law ao Ativismo Judicial. Revista Eletrônica Direito e Política, Programa de Pós-Graduação Stricto Sensu em Ciência Jurídica da UNIVALI, Itajaí, v.13, n.2, $2^{\circ}$ quadrimestre de 2018. Disponível em: www.univali.br/direitoepolitica - ISSN 1980-7791

O Common Law anglo-americano e o direito europeu continental, que agora regem a maioria da população mundial, tendem a se aproximar. O Common Law está passando por uma extensão dos statutes e das consolidations em detrimento do puro "judge made law", enquanto a jurisprudência vai assumindo importância crescente em muitos países de Civil Law. Por exemplo, naqueles países que têm um tribunal constitucional, o direito constitucional tende cada vez mais a se tornar um direito jurisprudencial. ${ }^{44}$

Destarte, o ativismo judicial, não somente vem dando crescente evidência ao Poder Judiciário, mas também tem proporcionado um movimento interessante, no qual "o civil law se aproxime do common law (não exatamente como o sistema inglês) com um evidente processo gradativo de emparelhamento de fontes primárias do direito entre a lei posta e decisões judiciais". ${ }^{45}$

Imperioso salientar que a aplicação do ativismo judicial vem se alterando com o passar do tempo. As mais diferentes cortes de todo o mundo vêm se utilizando do ativismo judicial em casos de grande repercussão política ou mesmo na implementação de políticas públicas, ao passo que sua utilização tem repercutido cada vez mais no cenário jurídico.

Na concepção de Cappelletti, isto ocorre porque a expansão do Poder Judiciário "representa o necessário contrapeso num sistema democrático de checks and balances à paralela expansão dos ramos políticos do Estado moderno". Nesta esteira, uma maior atividade estatal implica em mais insatisfação da população e, consequentemente, mais processos judiciais. ${ }^{46}$

\footnotetext{
44 LOSANO, Mario Giuseppe. Os grandes sistemas jurídicos: introdução aos sistemas jurídicos europeus e extra-europeus. São Paulo: Martins Fontes, 2007, p. 345.

45 BODNAR, Zenildo; CRUZ, Paulo Márcio. A commolização do direito positivo, o ativismo judicial e a crise do estado. Revista Novos Estudos Jurídicos, p. 1343.

${ }^{46}$ CAPPELLETTI, Mauro. Juízes legisladores? Porto Alegre: S. A. Fabris, 1993, p.19.
} 
RUDOLFO, Rafael Nunes Pires. Da Common Law ao Ativismo Judicial. Revista Eletrônica Direito e Política, Programa de Pós-Graduação Stricto Sensu em Ciência Jurídica da UNIVALI, Itajaí, v.13, n.2, $2^{\circ}$ quadrimestre de 2018. Disponível em: www.univali.br/direitoepolitica - ISSN 1980-7791

O ativismo judicial representa para a sociedade uma ferramenta que permite, através do poder judiciário, que o cidadão busque efetivar direitos não contemplados pela atuação dos demais poderes. É um tema polêmico e que merece bastante debate por parte dos operadores do direito, antes que se chegue a uma conclusão definitiva sobre sua utilização.

\section{CONSIDERAÇÕES FINAIS}

Como se pode constatar, o Ativismo Judicial tem suas origens ligadas ao common law, cuja origem está na Inglaterra. Pode-se perceber que o common law acabou se propagando pelas colônias britânicas (não somente nas treze colônias dos Estados Unidos), seja por imposição, seja por adoção ou influência. O fato é que o sistema, atualmente, é utilizado por mais de cinquenta países no mundo.

Conquanto muito se discuta sobre o contraste entre common law e civil law, a tendência parece ser no sentido de fusão entre os mencionados sistemas, escolhendo o que há de melhor de cada um.

Outrossim, pode-se observar como ocorreu o surgimento e a evolução do constitucionalismo e poder judiciário norte-americano, culminando com o fenômeno do ativismo judicial, o qual tem sido cada vez mais debatido e enaltecido pela doutrina e jurisprudência brasileira. Aliás, no Brasil, o Ativismo Judicial encontrou um "terreno fértil" para se popularizar: a falta de efetivação dos direitos fundamentais individuais e a inércia dos poderes executivo e legislativo. Destarte, no cenário brasileiro, o que se verifica é justamente a utilização do Ativismo Judicial enquanto ferramenta para a concretização dos direitos fundamentais e sociais, como por exemplo o direito à saúde, especialmente na ausência de políticas públicas adequadas (no caso, atribuição do Poder Executivo) ou mesmo na falta de legislação (atribuição do Poder Legislativo).

Por fim, a título de reflexão, as palavras extraídas dos ensinamentos de Aristóteles, já pareciam naquela época antecipar o estudo em testilha: 
RUDOLFO, Rafael Nunes Pires. Da Common Law ao Ativismo Judicial. Revista Eletrônica Direito e Política, Programa de Pós-Graduação Stricto Sensu em Ciência Jurídica da UNIVALI, Itajaí, v.13, n.2, $2^{\circ}$ quadrimestre de 2018. Disponível em: www.univali.br/direitoepolitica - ISSN 1980-7791

[...] toda lei é universal, mas não é possível fazer uma afirmação universal que seja correta em relação a certos casos particulares. Nos casos, portanto, em que é necessário falar de modo universal, mas não é possível fazê-lo corretamente, a lei leva em consideração o caso mais freqüente, embora não ignore a possibilidade de erro em consequência dessa circunstância. E nem por isso esse procedimento deixa de ser correto, pois o erro não está na lei nem no legislador, e sim na natureza do caso particular, já que os assuntos práticos são, por natureza, dessa espécie. Por conseguinte, quando a lei estabelece uma lei geral e surge um caso que não é abarcado por essa regra, então é correto (visto que o legislador falhou e errou por excesso de simplicidade), corrigir a omissão, dizendo o que o próprio legislador teria dito se estivesse presente, e que teria incluído na lei se tivesse previsto o caso em pauta. Por isso o equitativo é justo e superior a uma espécie de justiça, embora não seja superior à justiça absoluta, e sim ao erro decorrente do caráter absoluto da disposição legal. Desse modo, a natureza do eqüitativo é uma correção da lei quando esta é deficiente em razão da sua universalidade. É por isso que nem todas as coisas são determinadas pela lei: é impossível estabelecer uma lei acerca de algumas delas, de tal modo que se faz necessário um decreto. ${ }^{47}$

Imperioso salientar que este artigo não tem o intuito de alcançar nenhuma espécie de consenso, tampouco esgotar as discussões sobre o tema em testilha, mas sim analisar as origens e o contexto histórico no qual se formou o Ativismo Judicial. Destarte, o intuito foi justamente, através desta retrospectiva, entender o cenário atual em relação ao aludido fenômeno jurídico.

\section{REFERÊNCIAS DAS FONTES CITADAS}

ALVES, Fernando de Brito. Jurisdição constitucional e participação popular: sobre a possibilidade de novas relações entre o judiciário e o legislativo. Revista

Novos Estudos Jurídicos - Eletrônica, v. 19, n. 2. Itajaí: UNIVALI, 2014.

ARISTÓTELES. Ética a Nicômaco. Tradução de Pietro Nassetti. São Paulo: Editora Martin Claret, 2002.

BARROSO, Luis Roberto. A razão sem voto: a função representativa e majoritária das cortes constitucionais. Revista Estudos Institucionais, Vol. 2, n. 2, 2016.

${ }^{47}$ ARISTÓTELES. Ética a Nicômaco. Tradução de Pietro Nassetti. São Paulo: Editora Martin Claret, 2002. 
RUDOLFO, Rafael Nunes Pires. Da Common Law ao Ativismo Judicial. Revista Eletrônica Direito e Política, Programa de Pós-Graduação Stricto Sensu em Ciência Jurídica da UNIVALI, Itajaí, v.13, n.2, $2^{\circ}$ quadrimestre de 2018. Disponível em: www.univali.br/direitoepolitica - ISSN 1980-7791

BARROSO, Luís Roberto. Curso de direito constitucional contemporâneo: os conceitos fundamentais e a construção do novo modelo. São Paulo: Savaiva, 2009.

BODNAR, Zenildo; CRUZ, Paulo Márcio. A commolização do direito positivo, o ativismo judicial e a crise do estado. Revista Novos Estudos Jurídicos Eletrônica. Itajaí, v. 21, n. 3, 2016.

CAPELLARI, Eduardo. A crise da modernidade e a constituição: elementos para a compreensão do constitucionalismo contemporâneo. Dissertação (Mestrado em Direito). Universidade Federal de Santa Catarina. Florianópolis, 2002.

CAPPELLETTI, Mauro. Juízes legisladores? Porto Alegre: S. A. Fabris, 1993.

CONSANI, Cristina Foroni. O constitucionalismo republicano de Thomas Jefferson. Revista Novos Estudos Jurídicos - Eletrônica. Itajaí, v. 19, n. 3, 2014.

DWORKIN, Ronald. O império do direito. São Paulo: Martins Fontes, 1999.

EDLIN, Douglas E. "Judicial Review" sem uma constituição escrita. Cadernos do Programa de Pós-Graduação Direito/UFRGS, volume 10, n. 1, 2015.

FIORAVANTI, Maurizio. Constitución: de la Antiguidad a nuestros días. Tradução de Manuel Martínez Neira. Madrid: Trotta, 2001.

GONDIM, Yuri. O caso Marbury vs. Madison e a contribuição de John

Marshall. Jusbrasil, 2014. Disponível em:<

https://yurigondim.jusbrasil.com.br/artigos/118688828/o-caso-marbury-vs-

madison-e-a-contribuicao-de-john-marshall. > . Acesso em: 10 de março de 2017.

GUANDALINI JR., Walter. Perspectivas da tradição romanística: passado e futuro do direito romano. Sequência, Florianópolis, n. 70, jun. 2015.

KERTZMAN, Ivan. Curso prático de direito previdenciário. 11. ed. Salvador: Juspodivm, 2014.

LOSANO, Mario Giuseppe. Os grandes sistemas jurídicos: introdução aos sistemas jurídicos europeus e extra-europeus. São Paulo: Martins Fontes, 2007.

MADRUGA FILHO, Antenor Pereira. A noção de contrato no direito inglês:

perspectiva histórica. Revista de Informação Legislativa. Brasília, n. 143, p. 239-256, 1999. Disponível em:

https://www2.senado.leg.br/bdsf/bitstream/handle/id/518/r143-

19.PDF?sequence $=4$. Acesso em: 10/07/2017.

MATTEUCCI, Nicola. Organización del poder y libertad: historia del constitucionalismo moderno. Tradução de F. J. Ansuatpegui Roig e M. Martínez Neira. Madrid: Trotta, 1998. 
RUDOLFO, Rafael Nunes Pires. Da Common Law ao Ativismo Judicial. Revista Eletrônica Direito e Política, Programa de Pós-Graduação Stricto Sensu em Ciência Jurídica da UNIVALI, Itajaí, v.13, n.2, $2^{\circ}$ quadrimestre de 2018. Disponível em: www.univali.br/direitoepolitica - ISSN 1980-7791

MENEZES, Flavia Ferreira Jocó de; SILVA, Alexandre Garrido da. Poder judiciário e diálogos institucionais: uma perspectiva frente à flexibilização das decisões. Horizonte Científico, vol. 8, n. 1, julho de 2014.

NASCIMENTO, Aline Trindade do; WEIERS, Karine Schultz. Considerações sobre o ativismo judicial no Brasil. Revista Eletrônica Direito e Política, Programa de Pós-Graduação Stricto Sensu em Ciência Jurídica da UNIVALI, Itajaí, v.12, n. 1, 10 quadrimestre de 2017.

NISTLER, Regiane. A judicialização da política e a efetividade dos direitos sociais. Revista Eletrônica Direito e Política, Programa de Pós-Graduação Stricto Sensu em Ciência Jurídica da UNIVALI. Itajaí, v.11, n.1, 10 quadrimestre de 2016.

PASOLD, Cesar Luiz. Metodologia da pesquisa jurídica: teoria e prática. 13. ed. Florianópolis: Conceito Editorial, 2015.

PINTO, Felipe Chiarello de Souza; DONADELLI, Antonio Paulo de Mattos. O papel do judiciário, o estado de direito e o chamado "ativismo judicial" na doutrina brasileira. Revista Novos Estudos Jurídicos - Eletrônica. Itajaí, v. 19, n. 1, 2014.

RAMOS, Elival da Silva. Ativismo judicial: parâmetros dogmáticos. 2. ed. São Paulo: Saraiva, 2015.

RUDOLFO, Rafael Nunes Pires; PAVANELLO, Eliane. Ativismo judicial e o transporte público individual. Disponível em <https://jus.com.br/artigos/57229/ativismo-judicial-e-o-transporte-publicoindividual/1>. Acesso em: 17/07/2017.

SCHAUER, Frederick. Playing by the rules: a philosopical examination of rulebased decision-making in law and in life. Oxford University Press, 1991.

SCHAUER, Frederick. The force of law. Harvard University Press, 2015.

SILVA, Andrey Gastaldi; HEIL, Danielle Mariel. Paralelismo da legislação do modelo common law sobre a pena de morte e a redução da maioridade penal no ordenamento jurídico brasileiro. Revista Eletrônica Direito e Política, Programa de Pós-Graduação Stricto Sensu em Ciência Jurídica UNIVALI. Itajaí, v.11, n.3, $3^{\circ}$ quadrimestre de 2016.

SOLIANO, Vitor. Ativismo judicial no Brasil: uma definição. Revista Eletrônica Direito e Política, Programa de Pós-Graduação Stricto Sensu em Ciência Jurídica da UNIVALI. Itajaí, v.8, n.1, $1^{\circ}$ quadrimestre de 2013.

TASSINARI, Clarissa. Ativismo judicial: uma análise da atuação do Judiciário nas experiências brasileira e norte-americana. Dissertação (Mestrado em Direito). Universidade do Vale do Rio dos Sinos. São Leopoldo, 2012. 
RUDOLFO, Rafael Nunes Pires. Da Common Law ao Ativismo Judicial. Revista Eletrônica Direito e Política, Programa de Pós-Graduação Stricto Sensu em Ciência Jurídica da UNIVALI, Itajaí, v.13, n.2, $2^{\circ}$ quadrimestre de 2018. Disponível em: www.univali.br/direitoepolitica - ISSN 1980-7791

UROFSKY, Melvin I.; FINKELMAN, Paul. A march of liberty: a constitutional history of the United States. 2. ed., v.1. New York: Oxford University Press, 2002.

Recebido em: 17/05/2018

Aprovado em: 09/07/2018 